\title{
Manufacturing Parameters Optimization and Modeling of PxGyEz Hybrid Composite for High Flexural Strength Using Taguchi Robust Experimental Design Technique and General Regression Analysis
}

Bassey Okon Samuel ( $\square$ basseyokon59@gmail.com )

Ahmadu Bello University https://orcid.org/0000-0001-9104-7063

Research Article

Keywords: Optimization, Natural Fibers, Taguchi, Composites

Posted Date: August 24th, 2021

DOI: https://doi.org/10.21203/rs.3.rs-831643/v1

License: @ (i) This work is licensed under a Creative Commons Attribution 4.0 International License. Read Full License 


\title{
Manufacturing Parameters Optimization and Modeling of $\mathbf{P}_{\mathrm{x}} \mathrm{G}_{\mathrm{y}} \mathrm{E}^{\mathrm{z}}$ Hybrid Composite for High Flexural Strength Using Taguchi Robust Experimental Design Technique and General Regression Analysis
}

Authors:

Bassey Okon SAMUEL, *

Mechanical Engineering, Ahmadu Bello University, Zaria

basseyokon59@gmail.com

*Corresponding Author

\begin{abstract}
With the continuous need for sustainable, environmentally friendly, and low-cost systems, processes, and materials, natural fibers have been a major topic of discussion in the materials science community as it has increasingly found acceptance in material development as an alternative to synthetic fibers due to environmental concerns. Although many studies have been carried out in this regard, the optimal flexural performance of pineapple leaf fiber/synthetic fiber hybrid reinforced composite has not been studied even with its promising application in aviation, health, and fitness, marine, etc. In this study, a Pineapple Leaf fiber (PALF)/Glass fiber Epoxy hybrid composite $P_{x} G_{y} E^{z}$ (with $x$, $\mathrm{y}$, and $\mathrm{z}$ representing the volume fraction of pineapple leaf fiber, the volume fraction of glass fiber, and fiber length respectively) was developed and its flexural properties optimized and modeled with regards to the variable manufacturing parameters of $\mathrm{x}, \mathrm{y}$, and $\mathrm{z}$ respectively. For the quality characteristics (flexural strength) investigated, the Minitab®19 software was used to analyze the Taguchi robust experiment design technique on a higher the better basis. The optimum combination of the control factors was found at $\mathrm{x}=20 \%, \mathrm{y}=20 \%$, and $\mathrm{z}=25 \mathrm{~mm}$. The optimized composite $\mathrm{P}_{20} \mathrm{G}_{20} \mathrm{E}^{25}$ possessed a flexural strength of $144.4994 \mathrm{MPa}$ which was only a $7.17 \%$ deviation from the predicted optimum flexural strength. Analysis of variance showed that the PALF had the highest contribution of $23.97 \%$ to the flexural strength of the $\mathrm{P}_{\mathrm{x}} \mathrm{G}_{\mathrm{y}} \mathrm{E}^{\mathrm{z}}$, glass fiber $7.13 \%$, and fiber length $12.79 \%$. SEM Images of the PALF, glass fiber, and the fractured surface of the optimized material $\mathrm{P}_{20} \mathrm{G}_{20} \mathrm{E}^{25}$ revealed the surface structure which explained their different contribution to the flexural strength of the materials. An equation for the prediction of the flexural properties of $\mathrm{P}_{\mathrm{x}} \mathrm{G}_{\mathrm{y}} \mathrm{E}^{\mathrm{z}}$ was derived from the regression model and it had an approximately $77.57 \%$ agreement with experimentation.
\end{abstract}

Key Words: Optimization, Natural Fibers, Taguchi, Composites 


\subsection{Introduction}

One of the major discussions in the scientific community has been around the development of sustainable systems, processes, and materials (Paul et al., 2021; Sanchez-Rexach et al., 2020; Parv et al., 2021; Hardian et al., 2020; Tam et al., 2020). Fiber-reinforced polymer composites have found application in different industries due to their commendable strength to weight ratio Some of such applications include aircraft wings, wind turbines, ship hulls, physical fitness/health equipment, and prosthetics, etc. (Ozkan et al., 2020; Van Grootel et al., 2020; Nurazzi et al., 2021; Palani et al., 2021). Many studies have been carried out on different renewable sources of fibers used for the reinforcement of such composites (Madhu et al., 2020; Rangappa et al., 2020; Reis et al., 2020; Hassan et al., 2020). Natural cellulosic fibers like sisal leaf fiber, pineapple leaf fiber, palm fiber, banana fibers, etc. have increasingly been gaining traction due to their sustainability, environmental friendliness, and low cost (Sapuan et al., 2021; Alhijazi et al., 2020; Li et al., 2020; Periyasamy et al., 2020).

The flexural property is a major materials selection criteria for some of these applications as the forces in active service acts transverse to its major axis. These materials are expected to bear such flexural stress without failing (Estillore et al., 2021; Shaharuzaman et al., 2021; Gangwar et al.,2020; Ahmed et al., 2020; Mekonnen et al., 2020).

In recent times, there has been an exponential growth in computational power and this is coupled with improved algorithms. Advanced design requirements have been achieved by different researchers in various fields by applying these computational methods in carrying out analytical studies (Shalf, 2020; Abdulqadir et al., 2021; Mulenga et al. 2021). The challenges in physical complexities which are normally encountered in science and engineering research have been addressed by these modeling and optimization techniques (Jawahir et al., 2020; Mulengaet al., 2021). In the field of materials, researchers have been exploring these computational techniques to optimize the mechanical characteristics of these composite materials which are reinforced with natural fibers mostly to potentially replace synthetic fibers because of sustainability issues and environmental aspects. Several computational modeling and optimization techniques have been developed but one that stands out is the Taguchi design of experimental technique.

The ability to tailor and enhance composite materials properties to meet expected performances has increasingly made them find application in manufacturing and engineering. Such that with changes in its methods of preparation, constituents, features, etc., varying material behaviors or properties such as high flexural strength can be achieved to suit the intended application (Nayak et al., 2020; Vieira et al., 2020; Rajeshkumar et al., 2021). Some of the properties of these composite materials such as their mechanical strength (tensile strength, flexural strength, impact strength), fracture toughness, etc. have been improved through the years so much that they could be compared with conventional materials like steel (Kerni et al, 2020; Wang et al., 2020).

Natural fibers have more and more been used for the reinforcement of composite materials and this is not far from their exceptional features like environmental compatibility, low density, high impact strength, and some of them good flexural properties (Venkateshwaran et al., 2012; Wang et al., 2018). Natural fibers have been improving the mechanical properties of composites, serving as reinforcements, providing strength to the materials. These reinforcements could be in fibrous or non-fibrous (particulate) form. They are usually embedded in the matrix which serves the main purpose of holding the fibers in place and also transferring the stress from the loading point to the fibers. And they determine to a large extent, the durability, shape, environmental compatibility, and appearance of the composite materials (Omrani et al., 2016). Some well-known sources of natural fibers which have been explored for application in engineering, industrial, and consumer goods applications are banana, jute, coir, sisal, and kenaf (Wang et al., 2020). Sources like pineapple leaves have hardly been explored due to the setback of non-adhesiveness of the fibers with most polymer matrix materials (which is poor interfacial interaction between fiber and matrix) even though there have been attempts to surmount this setback by the surface modification of the fibers. With current findings, natural fiber composites have exhibited lesser mechanical properties in comparison with their counterpart synthetic fiber composites. Which is the reason why hybridization is normally employed to address this challenge. In hybridization, two or more fibers, which are dissimilar, are used in a single matrix to form a single material. An example is the hybridization of synthetic fiber with natural fibers. Hybridization can also be achieved by combining varying lengths and diameters of dissimilar short fibers, this approach has substantially improved the mechanical properties of these composites developed from natural fiber sources (Vijayakumar et al., 2019). In these natural fiber composites, the material behavior can be affected by different factors. Factors like the length of the fibers, the weight 
ratio of fiber compared with the matrix, orientation of the fiber in the composites, kind of fiber (source), methods of fabrication, methods of preparation/modification, etc. (Pappu et al., 2017; Jeyapragash et al., 2020).

\section{1 $\mathbf{P}_{\mathbf{x}} \mathbf{G}_{\mathbf{y}} \mathbf{E}^{\mathrm{z}}$ Hybrid Composite}

Developing materials from renewable sources with a high strength-to-weight ratio such that the flexural performance of the material is high in respect to its weight remains a challenging task for engineers and scientists (Parashar et al., 2021; Okokpujie et al., 2020; Jiang et al., 2020; Bratek-Skicki, 2021; Tu et a., 2021; Reddy et al., 2020). Natural fibers from plant materials have in recent times been exploited for applications in several industries due to their low density and environmental friendliness. But pineapple leaf fibers have been under-utilized due to their hydrophobic nature (Lee et al., 2020, Rajeshkumar et al., 2020). $\mathrm{P}_{\mathrm{x}} \mathrm{G}_{\mathrm{y}} \mathrm{E}^{\mathrm{z}}$ Hybrid Composite is a proposed hybrid composite material made up of Pineapple leaf fibers (PALF) with (X\% composition by volume), Glass fiber (with Y\% composition by volume), all with a fiber length of Zmm, in an Epoxy matrix. The composite seeks to exploit the high mechanical properties of synthetic fibers while taking advantage of the low density and eco-friendliness of natural fibers (pineapple leaf fiber). Glass fiber, although having commendable mechanical properties is non-biodegradable and the pineapple leaf fibers, being abundantly available due to its consideration as agro residue, has a low density and is environmentally friendly.

\subsection{Taguchi Optimization}

The Taguchi robust experimental design technique has been an important optimization process applied for the derivation of optimum processes or behaviors, and a powerful tool for the development or design of systems with high quality using individual and combined parameters from a minimum number of experimentations or simulation trials. Being a very important optimization process, the Taguchi technique is a powerful tool for the design of systems of high quality with individual and combined parameters and yet still a minimum number of experimental runs thereby reducing the cost of resources needed for the process (Basavarajappa et al., 2007; Taguchi et al., 1987; Taguchi, 1993). As stated earlier, in designing composites, the various factors that may affect the desired properties must be detailed. The fiber length and fiber content ratio have proven to be of influence in the mechanical behavior of the composite materials (Vijayakumar et al., 2019). This study explores the effect of the fiber content and the fiber length on the flexural property of the natural fiber reinforced polymer composite. The optimum strength with regards to the combination of these factors was achieved by the evaluation of the flexural strength of these composites.

Although studies have been carried out on the development of natural fiber reinforced polymer composites, the optimized flexural performance of pineapple leaf fiber hybridized with glass fiber as reinforcement in an epoxy matrix is still a grey area. This study will employ the Taguchi robust design to optimize the best combination of development factors of pineapple leaf fiber, glass fiber, and fiber length to achieve the optimum possible flexural strength of the $\mathrm{P}_{\mathrm{x}} \mathrm{G}_{\mathrm{y}} \mathrm{E}^{\mathrm{z}}$ hybrid composites within the constraints of these variable parameters. It will also model the behavior of these composite within these constraints.

\subsection{Experimental Methods}

\subsection{Fiber Preparation}

The fiber was extracted from pineapple leaf using the wet retting method. The chemical treatment was carried out in line with the procedure stated in (Mittal \& Chaudhary, 2018). After cleaning the cellulosic fiber and drying under the sun, the fibers were immersed in an alkali solution of $4 \mathrm{wt} \% \mathrm{NaOH}$ at room temperature for $24 \mathrm{hrs}$ and was thereafter treated with $2 \mathrm{wt} \%$ acetic acid $\left(\mathrm{CH}_{3} \mathrm{COOH}\right)$ solution. The $\mathrm{pH}$ was controlled at 7 by rinsing in distilled water. The treated fibers were then dried in an oven at $90^{\circ} \mathrm{C}$ for $24 \mathrm{hrs}$ until the weight became constant (i.e. there was no more weight loss due to moisture loss. The glass fiber was procured directly from Maersk Chemicals (Sigma Aldrich). The fibers were then cut in appropriate lengths as needed.

\subsection{Composite Preparation}

The volume of the matrix (epoxy and hardener) required was calculated by multiplying the dimensions of the steel mold with the required thickness of the composite to be molded. The required amount of the epoxy and hardener was calculated by weight in the ratio of 5:1. This research employed the stir cast open mold (hand lay-up process) as described in (Nagavally, 2016), i.e., directly casting in an open mold, for the manufacturing of the composites. 
During the fabrication process, the PALF and glass fiber, after being cut into the lengths as described in the orthogonal array, was soaked with the matrix which is unsaturated epoxy resin. Before casting, a releasing agent (wax) was applied to the surface of the mold to enhance the easy removal after fabrication, then the mixed resin and fibers were poured into the mold. Voids were removed from the materials by the use of brushes and hand rollers and to spread the resin evenly throughout the fibers. The mold was transferred to the simple press to force all air which was between the fiber and resin out and it was left under pressure for $72 \mathrm{hrs}$ in other to obtain the perfect samples. Upon complete setting (hardening) of the hybrid composite, the mold was released from the press and the rough edges trimmed to the shape of the mold. Curing of the laminated hybrid composites was carried out by exposure to atmospheric conditions. Samples for the flexural test were then obtained from the cured composites by cutting to shape using a grinding machine.

\subsection{Flexural Test}

The flexural test was conducted according to ASTM D790 using the ENERPAC P391 material testing machine. The flexural modulus (MOR), was calculated using

$$
M O R=\frac{3 P S}{2 b t^{2}}
$$

Where $S$ is the span length of the sample (gauge length). $\mathrm{P}$ is the load applied; $\mathrm{b}$ and $\mathrm{t}$ are the width and thickness of the specimen respectively.

\subsection{Taguchi Approach to Robust Parameter Design}

In this study, optimization of the flexural strength by variation of design parameters through the Taguchi approach is used along with orthogonal arrays (OAs) in the statistical experimental design method. Using this method enables us to observe the effects of Pineapple leaf fibers volume content, glass fiber volume content, and fiber length on the flexural strength of the hybrid composite. Table 1 shows the different factors considered and their various levels. According to Taguchi, the $\mathrm{S} / \mathrm{N}$ ratio is a measure of the deviation of our measured effect from the desired values. For the analysis with regards to the SN ratio, the effects measured could be categorized into three classes which are the higher the better, the lower the better and the nominal the best. Flexural strength is regarded in the class of the higher the better implying that the higher flexural strength is desired and corresponds to the optimal level of the process parameters. SN ratio for the Higher the better characteristics is derived from equation (2)

$$
\left(\frac{S}{N}\right)_{H T B}=-10 * \log _{10}\left(\frac{1}{n} \sum_{i=1}^{n} \frac{1}{y_{i}^{2}}\right)
$$

Where $\mathrm{n}$ represents the number of experimentations, $y_{i}$ represents the response value (flexural strength) of the $i^{\text {th }}$ experiment in the orthogonal array. Also, $(\mathrm{S} / \mathrm{N})$ represents the signal-to-noise ratio, and the acronym HTB stands for the Higher the Better. The Minitab® 19 software was employed for the analysis of the result, while the Origin Pro $2019 \mathrm{~b}$ software was used for the graphical illustrations of the results.

The factors that were considered in this optimization process and their levels are presented in Table1.

\begin{tabular}{|c|c|c|c|c|c|}
\hline \multirow{2}{*}{$\mathbf{S} / \mathbf{N}$} & \multirow{2}{*}{ Processing Factors } & \multirow{2}{*}{$\begin{array}{c}\text { Factors } \\
\text { Designation }\end{array}$} & \multicolumn{3}{|c|}{ Level } \\
\hline & & & 1 & 2 & 3 \\
\hline 1 & PALF Volume Fraction (\%) & $\mathrm{x}$ & 10 & 15 & 20 \\
\hline 2 & Glass Fiber Volume Fraction (\%) & $\mathrm{y}$ & 20 & 15 & 10 \\
\hline 3 & Fiber Length $(\mathrm{mm})$ & $\mathrm{z}$ & 15 & 20 & 25 \\
\hline
\end{tabular}

Table 1: Variable parameters and their levels

Table 1 shows the experimental design with three factors at three levels for the fabrication of the PLAF/GL Epoxy $\left(\mathrm{P}_{\mathrm{x}} \mathrm{G}_{\mathrm{y}} \mathrm{E}^{\mathrm{z}}\right)$ Hybrid composite.
x: Pineapple Leaf fiber vol.\%
y: Glass Fiber vol.\%
z: Fiber Length mm 
For the three-factor three-level experiment: equation (3) gives the minimum number of experimental runs to be carried out:

$$
N_{\text {Taguchi }}=1+N(L-1)
$$

Where $\mathrm{N}_{\text {Taguchi }}$ is the minimum number of trials to be conducted; $\mathrm{N}$ is the number of variable parameters, while $\mathrm{L}$ is the number of levels for the control factors (variable parameters), and from Table 1 above, $\mathrm{N}=3, \mathrm{~L}=3$. Therefore $\mathrm{N}_{\text {Taguchi }}=9$.

From the Taguchi Orthogonal array Table, the 3 factors 3 levels, the number of experimentations to be carried out is 9 and 27, in other to reduce the number of experiments, we go for the minimum which is nine. Minitab®19 was then used to generate Table 2 where the factor combinations in the experimental runs are presented.

Table 2: The Result of Orthogonal Test L9

\begin{tabular}{cccc}
\hline Trial No. & \multicolumn{3}{c}{ Levels of parameter Settings } \\
\cline { 2 - 4 } & $\begin{array}{c}\text { PALF Volume Fraction } \\
(\mathbf{x})\end{array}$ & $\begin{array}{c}\text { Fiber } \\
\text { Fraction }(\mathbf{y})\end{array}$ & $\begin{array}{c}\text { Length }(\mathbf{z}) \\
\text { (10 }\end{array}$ \\
\hline 1 & 10 & 20 & 15 \\
3 & 10 & 15 & 20 \\
4 & 15 & 10 & 25 \\
5 & 15 & 20 & 20 \\
6 & 15 & 15 & 25 \\
7 & 20 & 10 & 15 \\
8 & 20 & 20 & 25 \\
9 & 20 & 15 & 15 \\
\hline
\end{tabular}

Each test was replicated three times for repeatability. 


\subsection{Results and Discussions}

Using the orthogonal array as presented in Table 2 which is a combination of the different variable parameters at different levels, the mean flexural strength of all the runs was observed to be $98.212 \mathrm{MPa}$ and the mean SN ratio was observed to be $39.7024 \mathrm{~dB}$. The result of the mean and SN ratio of the different combinations are presented in Table 3.

Table 3: Results of Mean and SN Ratio of Flexural Strength of PALF/Glass Fiber Epoxy Hybrid composite

\begin{tabular}{|c|c|c|c|c|c|}
\hline \multirow{2}{*}{$\begin{array}{c}\text { Trial No. } \\
1\end{array}$} & \multicolumn{3}{|c|}{ Raw Data (Flexural Strength (MPa)) } & \multirow{2}{*}{$\begin{array}{c}\text { Mean (MPa) } \\
92.818\end{array}$} & \multirow{2}{*}{$\begin{array}{c}\mathbf{S} / \mathbf{N} \text { ratio }(\mathbf{d B}) \\
39.3506\end{array}$} \\
\hline & 91.449 & 92.690 & 94.316 & & \\
\hline 2 & 91.818 & 92.690 & 92.690 & 92.399 & 39.3131 \\
\hline 3 & 95.694 & 93.391 & 92.690 & 93.925 & 39.4532 \\
\hline 4 & 93.333 & 97.627 & 93.010 & 94.657 & 39.5167 \\
\hline 5 & 79.997 & 74.405 & 78.161 & 77.521 & 37.7764 \\
\hline 6 & 86.367 & 86.069 & 87.719 & 86.718 & 38.7613 \\
\hline 7 & 143.678 & 144.164 & 145.655 & 144.499 & 43.1969 \\
\hline 8 & 86.367 & 87.558 & 86.969 & 86.964 & 38.7864 \\
\hline 9 & 114.526 & 112.552 & 116.144 & 114.407 & 41.1669 \\
\hline Mean & & & & 98.212 & 39.7024 \\
\hline
\end{tabular}

The response Table for the mean and SN ratio are presented in Table 4. Each was derived from averaging the measured responses of the factors at each level. Such that:

$$
S_{P i}=\frac{\sum_{n=1}^{9} \eta_{i n}}{l}
$$

Where $S_{P i}$ represents the average response of factor $\mathrm{P}(\mathrm{X}, \mathrm{Y}, \mathrm{Z})$ at level $\mathrm{i} ; n$ is the experiment number; $\eta_{i n}$ is the result of the $\mathrm{S} / \mathrm{N}$ ratio or mean at level $i$ appearing within the number of runs; $l$ is the number of levels. Table 4 presents the response Table for the mean and $\mathrm{SN}$ ratio.

Table 4: Flexural Strength Response Table (Means and S/N ratio)

\begin{tabular}{ccccccc}
\hline \multirow{2}{*}{ Level } & \multicolumn{2}{c}{$\begin{array}{c}\text { PALF Content } \\
(\mathbf{X})\end{array}$} & \multicolumn{2}{c}{$\begin{array}{c}\text { Glass Fiber Content } \\
(\mathbf{Y})\end{array}$} & \multicolumn{2}{c}{$\begin{array}{c}\text { Fiber Length } \\
(\mathbf{Z})\end{array}$} \\
\cline { 2 - 7 } & Mean & S/N Ratio & Mean & S/N Ratio & Mean & S/N Ratio \\
\hline 1 & 93.05 & 39.37 & 110.66 & 40.69 & 88.83 & 38.97 \\
2 & 86.30 & 38.68 & 85.63 & 38.63 & 100.49 & 40.00 \\
3 & 115.29 & 41.05 & 98.35 & 39.79 & 105.31 & 40.14 \\
Delta & 28.99 & 2.37 & 25.03 & 2.06 & 16.48 & 1.18 \\
Rank & 1 & 1 & 2 & 2 & 3 & 3 \\
\hline
\end{tabular}




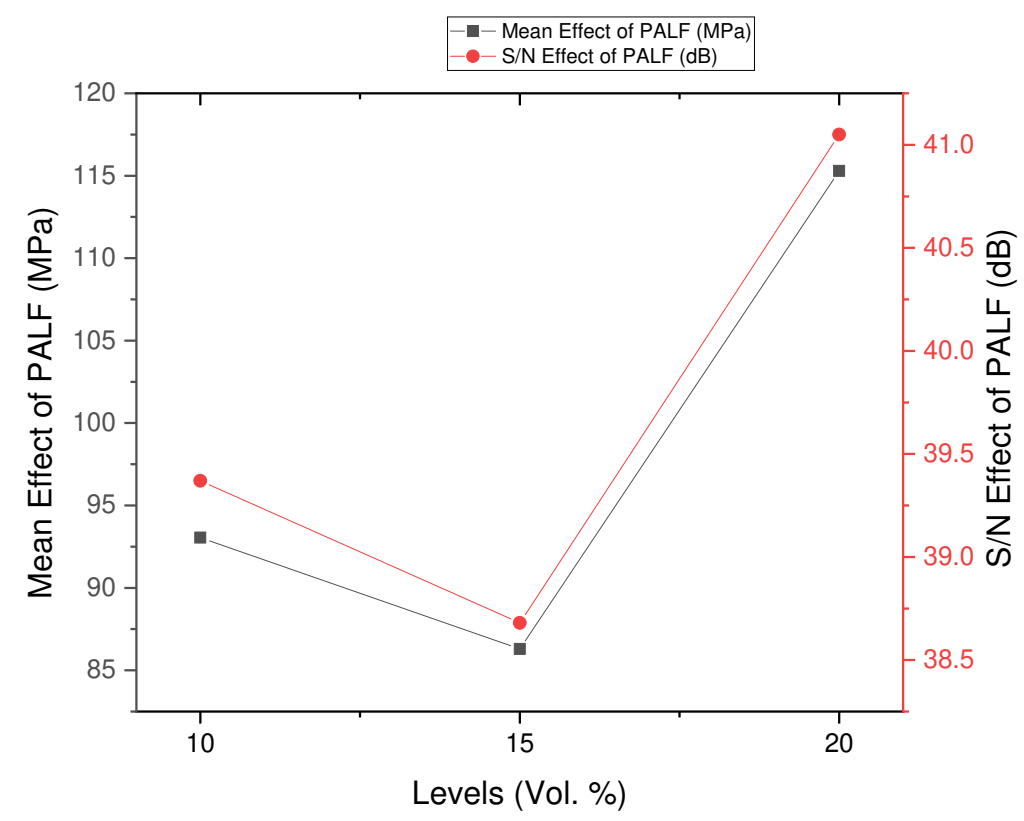

Figure1a: Effect of PALF on the Flexural Strength of $\mathrm{P}_{\mathrm{x}} \mathrm{G}_{\mathrm{y}} \mathrm{E}^{\mathrm{z}}$ (Mean and $\mathrm{S} / \mathrm{N}$ )

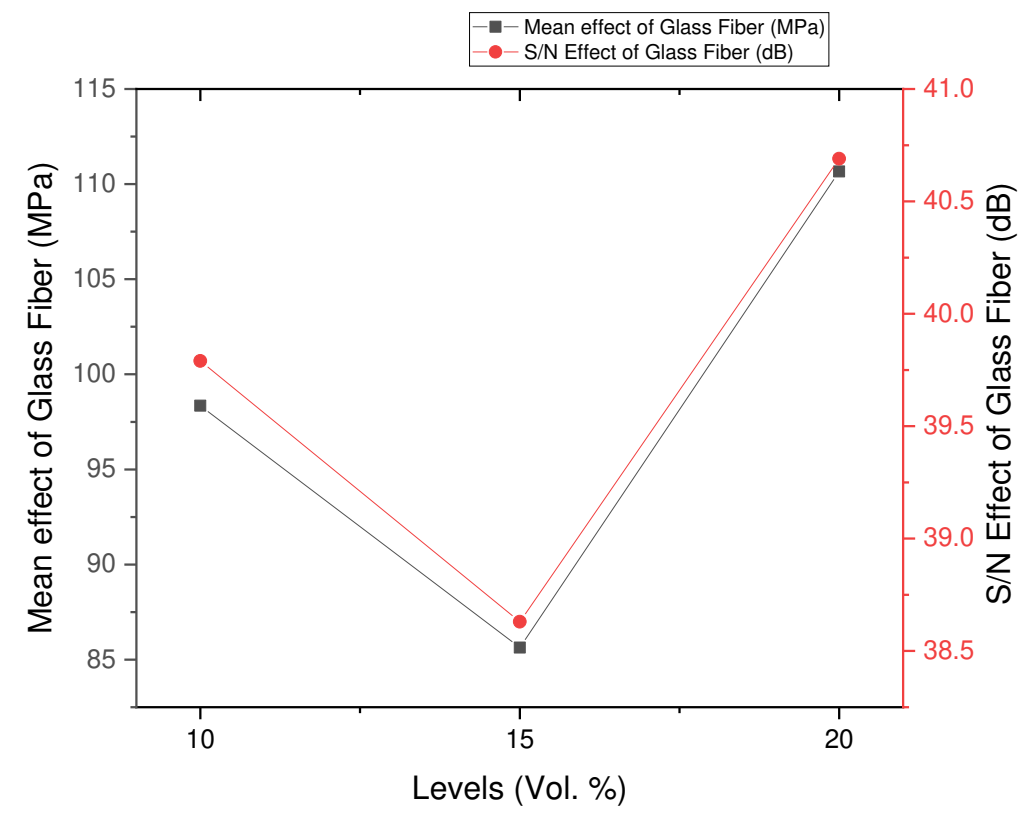

Figure 1b: Effect of Glass Fiber on the Flexural Strength of $\mathrm{P}_{\mathrm{x}} \mathrm{G}_{\mathrm{y}} \mathrm{E}^{\mathrm{z}}$ (Mean and $\mathrm{S} / \mathrm{N}$ ) 


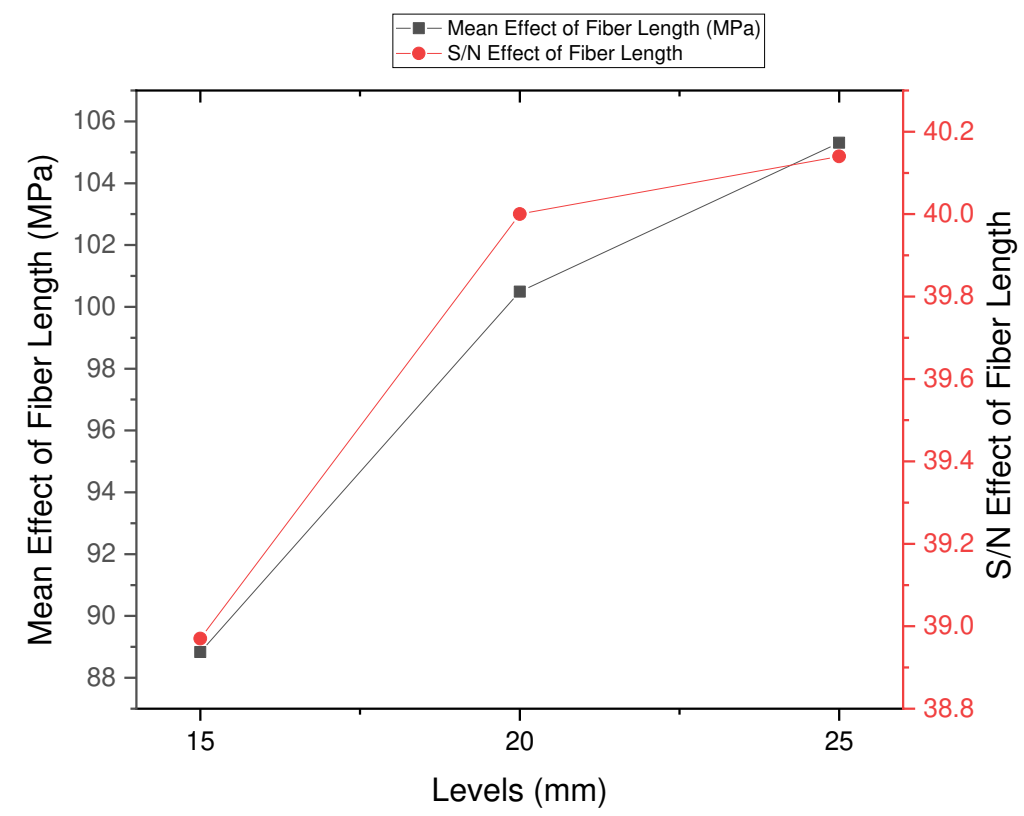

Figure 1c: Effect of Fiber Length on the Flexural Strength of $\mathrm{P}_{\mathrm{x}} \mathrm{G}_{\mathrm{y}} \mathrm{E}^{\mathrm{z}}($ Mean and $\mathrm{S} / \mathrm{N})$

Figure 1(a-c) graphically illustrates the effect of the various variable parameters on the flexural strength of $\mathrm{P}_{x} \mathrm{G}_{\mathrm{y}} \mathrm{E}^{\mathrm{z}}$. In Figure 1a, it is seen that the flexural strength of the $\mathrm{P}_{\mathrm{x}} \mathrm{G}_{\mathrm{y}} \mathrm{E}^{\mathrm{z}}$ hybrid composites generally increases with the increase in the amount of PALF fiber in it. With the highest performance of $115 \mathrm{MPa}$ at $20 \%$ volume content of the fiber. Also, from Figure 1b, there was a general increase in flexural strength with an increase in glass fiber with a peak of $110 \mathrm{MPa}$ at $20 \%$ glass fiber content. This observed increase is due to the increased amount of fiber in the composite making it easier for stress to be transferred from the matrix to the fiber at higher volume content. Also, the agglomeration of fibers at higher content may have a positive effect on flexural strength. Figure $1 \mathrm{c}$ shows that there is a constant increase in flexural strength with a corresponding increase in fiber length. This is not be disconnected from the reason that at higher fiber length, there is a lower possibility of fibrillation (an instance where the ends of the fiber acts as the failure initiation points, and with a lower number of ends, there is a lower possibility for crack or failure in the composite). Therefore the optimized combination to produce the best flexural strength in the $\mathrm{P}_{\mathrm{x}} \mathrm{G}_{\mathrm{y}} \mathrm{E}^{\mathrm{z}}$ hybrid composite is $20 \%$ volume content of PALF, $20 \%$ volume content of glass fiber, and $25 \mathrm{~mm}$ of the fiber length. Therefore the optimized form of the $\mathrm{P}_{\mathrm{x}} \mathrm{G}_{\mathrm{y}} \mathrm{E}^{\mathrm{z}}$ hybrid composite is $\mathrm{P}_{20} \mathrm{G}_{20} \mathrm{E}^{25}$. 

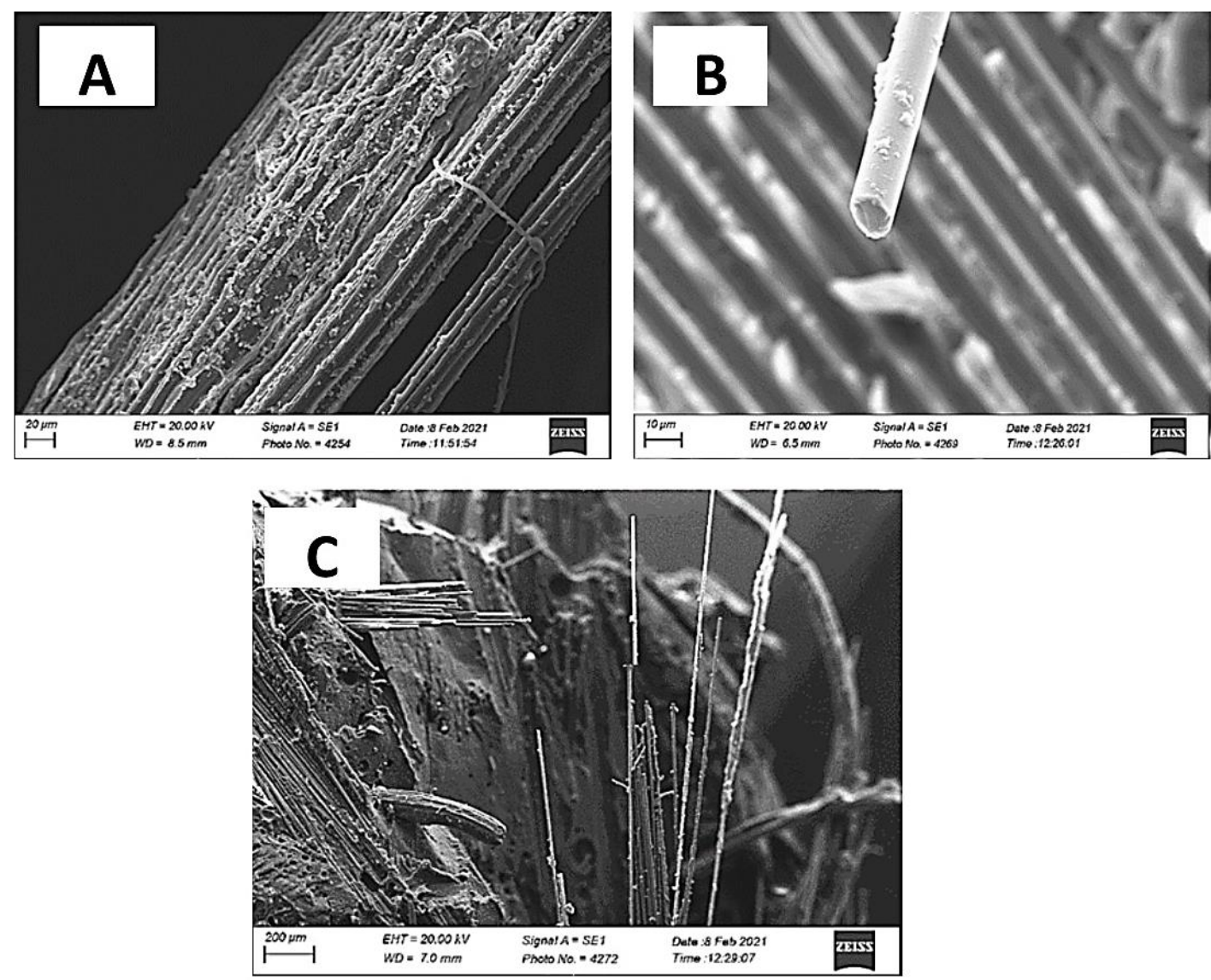

Figure 2: SEM Images of (A) Treated pineapple leaf fiber (B) Glass Fiber (C) $\mathrm{P}_{20} \mathrm{G}_{20} \mathrm{E}^{25}$ fractured surface.

Figure 2 shows the SEM images of the fiber, glass fiber, and the optimized $\mathrm{P}_{20} \mathrm{G}_{20} \mathrm{E}^{25}$ composite. In Figure $2 \mathrm{a}$, the rough and ridge-like surface of the treated pineapple leaf fiber gives it an advantage of adhesion in the composite. Also, Figure $2 \mathrm{~b}$ shows the adhesion of the matrix material to the surface of the glass fiber at the fracture area. This good adhesion enhances the flexural strength of the material. 


\subsection{Analysis of Variance (ANOVA)}

The analysis of variance is used to understand the percentage contribution of each factor (variable parameter) on the measured effect (flexural strength). In this situation, the ANOVA is used to determine the level of contribution of PALF, glass fiber, and fiber length to the flexural strength of the developed composite. The ANOVA for the mean effect and the SN ratios are presented in Tables 5 and 6 respectively.

\section{Analysis of Variance for Means}

Table 5: Analysis of Variance of Means for Fexural Strength of PALF/Glass Fiber Epoxy Hybrid composite.

\begin{tabular}{|c|c|c|c|c|c|c|c|}
\hline Source & DF & Seq SS & Adj SS & Adj MS & $\begin{array}{c}\text { Fishers Test: } \\
\text { F }\end{array}$ & $\mathbf{P}$ & $\begin{array}{c}\% \\
\text { Contribution } \\
(\%) \\
\end{array}$ \\
\hline Regression & 6 & 2470.78 & 2470.78 & 411.80 & 1.15246 & 0.533338 & \\
\hline $\begin{array}{l}\text { PALF Content } \\
(\%) ; x\end{array}$ & 1 & 742.10 & 845.03 & 845.03 & 2.36492 & 0.263929 & 23.297 \\
\hline $\begin{array}{c}\text { Glass Fiber } \\
\text { Content }(\%) ; \mathrm{y}\end{array}$ & 1 & 227.23 & 8.49 & 8.49 & 0.02377 & 0.891616 & 7.134 \\
\hline $\begin{array}{l}\text { Fiber Length } \\
\quad(\mathrm{mm}) ; \mathrm{z}\end{array}$ & 1 & 407.47 & 354.85 & 354.85 & 0.99308 & 0.423986 & 12.792 \\
\hline $\mathrm{x} * \mathrm{y}$ & 1 & 16.78 & 509.49 & 509.49 & 1.42588 & 0.354858 & 0.527 \\
\hline $\mathrm{X} * \mathrm{Z}$ & 1 & 783.26 & 1042.63 & 1042.63 & 2.91793 & 0.229724 & 24.589 \\
\hline $\mathrm{y}^{*} \mathrm{z}$ & 1 & 293.94 & 293.94 & 293.94 & 0.82262 & 0.460149 & 9.228 \\
\hline Error & 2 & 714.64 & 714.64 & 357.32 & & & 22.435 \\
\hline Total & 8 & 3185.41 & & & & & \\
\hline
\end{tabular}

Tabulated F-ratio at 95\% confident level

\section{Analysis of Variance for SN Ratio}

Table 6: Analysis of Variance of SN Ratio for Flexural Strength of PALF/Glass Fiber Epoxy Hybrid composite.

\begin{tabular}{|c|c|c|c|c|c|c|c|}
\hline Source & DF & Seq SS & Adj SS & Adj MS & $\begin{array}{c}\text { Fishers Test: } \\
\text { F }\end{array}$ & $\mathbf{P}$ & $\begin{array}{c}\% \\
\text { Contribution } \\
(\%)\end{array}$ \\
\hline Regression & 6 & 14.3232 & 14.3232 & 2.38720 & 0.81764 & 0.641498 & \\
\hline $\begin{array}{l}\text { PALF Content } \\
(\%) ; \mathrm{x}\end{array}$ & 1 & 4.2224 & 5.3418 & 5.34185 & 1.82965 & 0.308799 & 20.942 \\
\hline $\begin{array}{c}\text { Glass Fiber } \\
\text { Content (\%); y }\end{array}$ & 1 & 1.1996 & 0.0084 & 0.00836 & 0.00286 & 0.962200 & 5.9497 \\
\hline $\begin{array}{l}\text { Fiber Length } \\
\quad(\mathrm{mm}) ; \mathrm{z}\end{array}$ & 1 & 2.0747 & 2.0010 & 2.00098 & 0.68536 & 0.494806 & 10.29 \\
\hline$x^{*} y$ & 1 & 0.0543 & 3.1631 & 3.16306 & 1.08339 & 0.407242 & 0.2693 \\
\hline$x^{*} \mathrm{z}$ & 1 & 4.6173 & 6.6577 & 6.65774 & 2.28036 & 0.270103 & 22.901 \\
\hline $\mathrm{y}^{*} \mathrm{z}$ & 1 & 2.1549 & 2.1549 & 2.15492 & 0.73809 & 0.480806 & 10.688 \\
\hline Error & 2 & 5.8392 & 5.8392 & 2.91961 & & & 28.961 \\
\hline Total & 8 & 20.1624 & & & & & \\
\hline
\end{tabular}

Tabulated F-ratio at 95\% confidence level, DF= Degree of freedom, SS=Sum of Square, MS=Mean Square

The assertions from the physical observations in the SEM images of Figure 2 was corroborated by the analysis of variance presented in Table 5 and 6 , it is observed that PALF have the highest contribution of $23.29 \%$ to the flexural strength of the optimized $\mathrm{P}_{20} \mathrm{G}_{20} \mathrm{E}^{25}$ hybrid composite. With the glass fiber and fiber length contributing $7.133 \%$ and $12.792 \%$ respectively. The failure pattern of the glass fibers as shown in Figure $2 \mathrm{c}$ indicates the brittle nature of the glass fiber thereby having less flexural strength, even though that attribute may not be detrimental to its tensile strength, even as a material brittleness influences its flexural strength. Figure $2 \mathrm{c}$ shows also show the PALF in a bent 
position, indicating its ductility compared to the glass fiber. And this may explain its more contribution to the flexural strength of the composite. The results indicate that the more PALF in the composite, the more the flexural strength of the material. The analysis was carried out at a $95 \%$ confidence level.

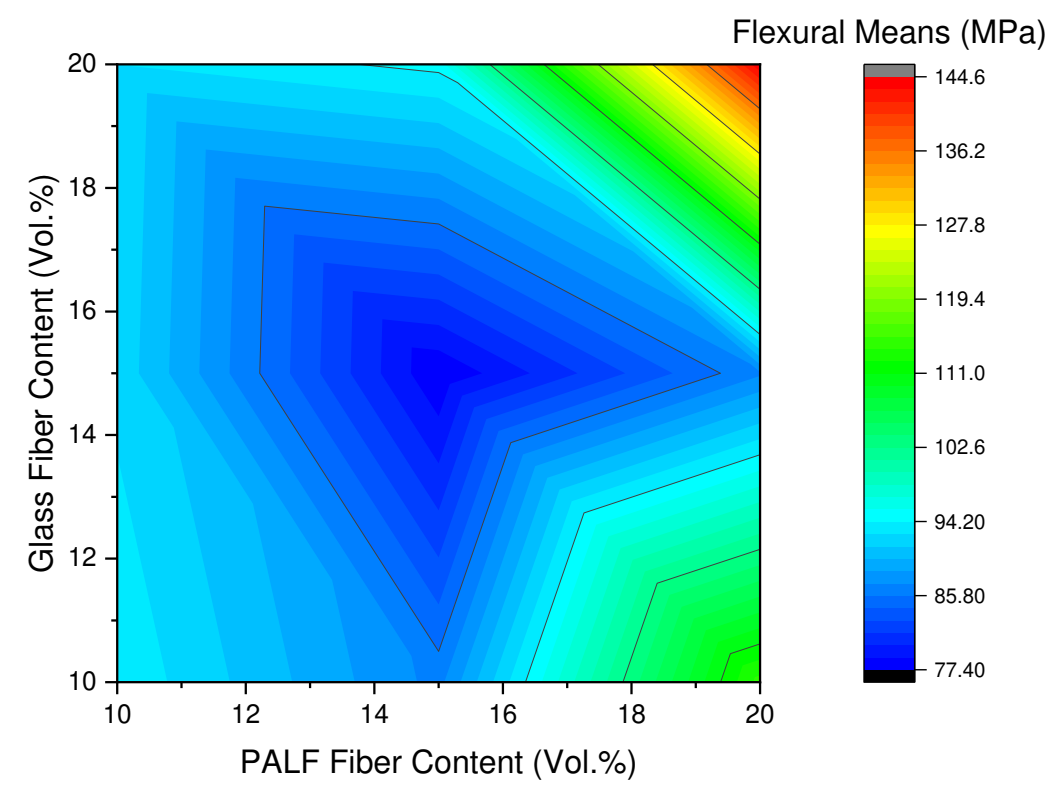

Figure 3a: Surface plot of the interaction of PALF fiber content with glass fiber content.

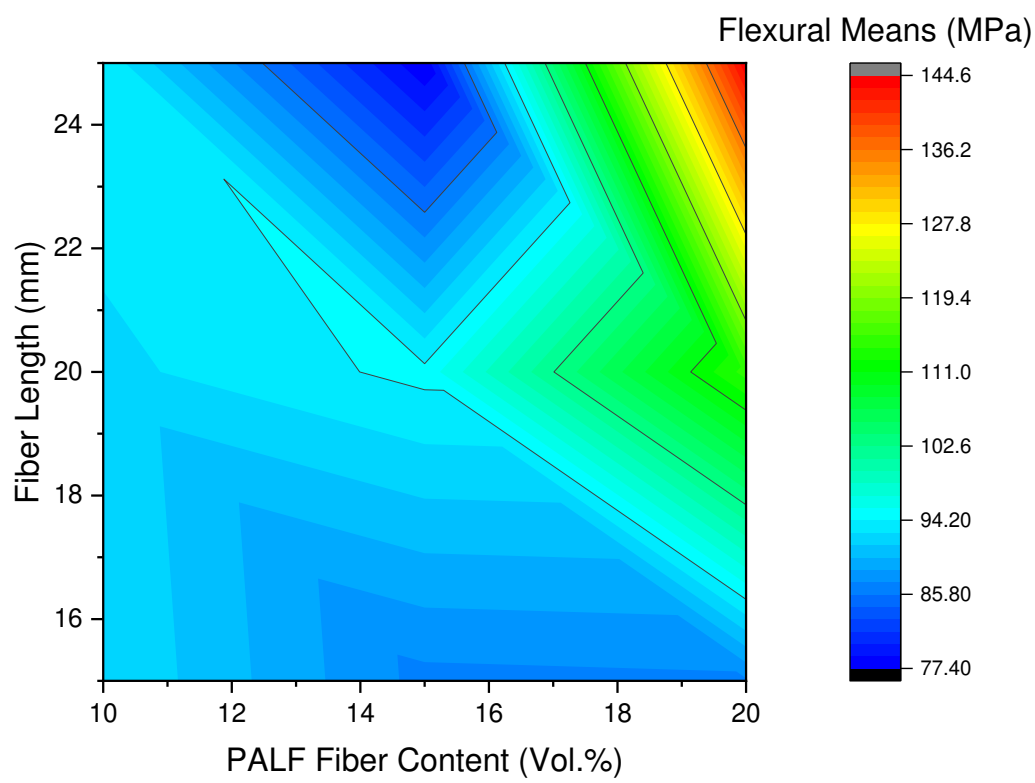

Figure 3b: Surface plot of the interaction of PALF fiber content with fiber length 


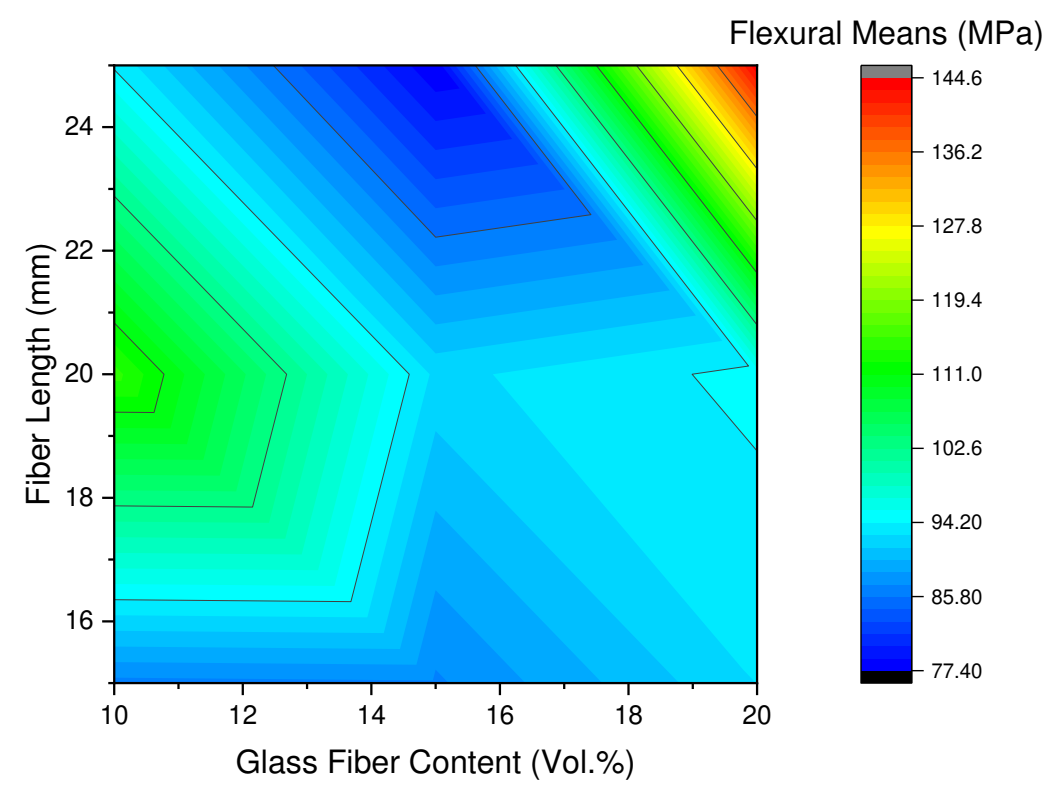

Figure 3b: Surface plot of the interaction of glass fiber with fiber length

The interaction of the factors considered in the optimization of the $\mathrm{P}_{\mathrm{x}} \mathrm{G}_{\mathrm{y}} \mathrm{E}^{\mathrm{z}}$ for high flexural strength is presented in the surface plots of Figure 3(a-c). Figure 3a shows that higher flexural strength was obtained at points of the higher fiber content of both PALF and Glass fiber. This is because of the resultant increase in overall fiber volume content with the increase in the fiber volume content of each of the fibers under study. Also, it has been reported that an increase in fiber volume content generally results in an improved mechanical property, although with a decline upon exceeding a saturation limit where stress is inefficiently transferred from the matrix to the reinforcements (HerreraFranco et al., 2005). The ANOVA as presented in Table 5 shows a percentage contribution of the interaction of PALF content and glass fiber content as $0.53 \%$. So also with the interaction of PALF with fiber length as shown in Figure $3 \mathrm{~b}$ where the best flexural properties were observed at the points of the highest PALF fiber content and longest fiber length. The length of the pineapple leaf fiber increases the possibility of favorable fiber-to-fiber interactions like entanglements and the reduction in the fibrillations (failure initiation points). This is a critical consideration for the flexural strength of the composite as this interaction proved to contribute about $24.59 \%$ to the flexural strength of the composite as shown in Table 5. Also with a percentage contribution of $9.228 \%$ on the flexural strength of the interaction of glass fiber content with fiber length as presented in Table 5, Figure $3 \mathrm{~b}$ shows a higher flexural strength at the highest glass fiber content and longest fibers. This is due to the brittleness of the glass fibers as observed in its failure pattern shown in the SEM images of Figure 2c. The longer the fiber, the more flexible it is and therefore its higher resistance to flexural stress. Good flexural strength was also observed at low glass fiber contents of $14 \%$ and length within regions of $18-22 \mathrm{~mm}$ as shown in Figure $3 \mathrm{~b}$.

\subsection{Estimating the Optimal Flexural Strength}

Using the optimal settings of the control factors (x1y1z3), an optimal flexural strength for the hybrid material $P_{x} G_{y} E^{z}$ can be predicted using the expression;

$$
T_{o p t}=T_{m}+\sum_{k=1}^{k_{n}}\left[\left(T_{i k}\right)_{\max }-T_{m}\right]
$$

Where: $T_{m}=98.212 \mathrm{MPa}$ is the overall mean or $\mathrm{S} / \mathrm{N}$ ratio obtained from Table 3;

$T_{i k \max }=115.29 \mathrm{MPa}, 110.66 \mathrm{MPa}$, and $105.31 \mathrm{MPa}$ is the mean or $\mathrm{S} / \mathrm{N}$ ratio at optimum level $\mathrm{i}$ of factor $\mathrm{k}$ (obtained from Table 4) and $k_{n}$ is the number of main design factors that affect the response (=3; PALF, glass fiber, and fiber 
length). $T_{i k m a x}$ is gotten from the response Table of mean or $\mathrm{S} / \mathrm{N}$ ratio in which for each parameter on the Table, the highest value among the levels is the $T_{i k m a x}$.

Therefore, the optimal flexural strength is:

$$
\begin{gathered}
T_{\text {opt }}=98.212+(110.66-98.212)+(115.29-98.212)+(105.31-98.212) \\
T_{o p t}=134.836 \mathrm{MPa}
\end{gathered}
$$

In other to calculate a confidence interval C.I,

$$
C . I=\sqrt{F_{\alpha}\left(1, F_{e}\right) V_{e}\left[\frac{1}{\eta_{e f f}}+\frac{1}{\eta_{v e r}}\right]}
$$

Where; $\mathrm{C}$. $\mathrm{I}=$ Confidence interval; $\mathrm{F}_{\alpha}\left(1, \mathrm{~F}_{\mathrm{e}}\right)=\mathrm{F}$ ratio required for $\alpha ; \alpha=$ Risk; $\mathrm{F}_{\mathrm{e}}=$ Error DOF; $\mathrm{F}_{\alpha}\left(1, \mathrm{~F}_{\mathrm{e}}\right)=$ $\mathrm{F}_{0.05}(1,2)=18.51 \quad$ (tabulated), $\mathrm{V}_{\mathrm{e}}=$ Error Variance (obtained from the ANOVA Table) $=714.64 ; \quad \eta_{\mathrm{ver}}=$ number of trials to run confirmation test i.e. same as the number of replication for each run $=3$; $\eta_{\text {eff }}=$ Effective number of replications

$$
\eta_{\text {eff }}=\frac{N}{1+[\text { Total DOF of controlled factors }]}
$$

$\mathrm{N}=$ Total number of results $=27$, Total DOF (degree of freedom) of controlled factors $=6$

Therefore $\eta_{\text {eff }}=3.85$

$$
C . I=\sqrt{18.51 \times 714.64\left[\frac{1}{3.85}+\frac{1}{3}\right]}
$$

Therefore C.I $= \pm 88.57 \mathrm{MPa}$

\subsection{Confirmation test}

The $\mathrm{P}_{20} \mathrm{G}_{20} \mathrm{E}^{25}$ optimized composite was fabricated using the optimized composition as obtained which is PALF fiber at $20 \%$, glass fiber at $20 \%$, and fiber length at $25 \mathrm{~mm}$. Three samples were cut out and flexural tests were carried out according to the ASTM D790 flexural test procedures. The result of the flexural test is presented in Table 7. The average flexural strength was found to be $144.499 \mathrm{MPa}$ with an SN Ratio of $43.1969 \mathrm{~dB}$.

Table 7: Observation of confirmation test (flexural strength)

\section{Trial Number}

\begin{tabular}{cccccc}
\hline & $\mathbf{1}$ & $\mathbf{2}$ & $\mathbf{3}$ & $\begin{array}{c}\text { Average Flexural Strength } \\
(\mathbf{M P a})\end{array}$ & SN Ratio (dB) \\
\hline 1 & 143.678 & 144.164 & 145.655 & 144.499 & 43.1969 \\
\hline
\end{tabular}

The obtained flexural test from the confirmatory test shows that the experimental value lies between the confidence interval range of the flexural strength such that Predictive value - C.I $<$ Experimental value $<$ Predictive value + C.I.

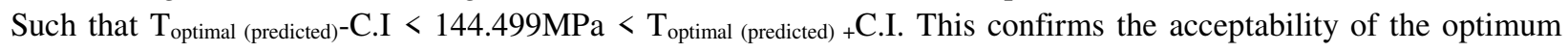
flexural strength prediction.

\subsection{Regression Analysis}

A mathematical model for the combination of PALF in volume percentage, glass fiber in volume percentage, and fiber length in millimeters was obtained from the regression analysis carried out using the MINITAB ${ }^{\circledR} 19$ statistical software used for the prediction of the flexural strength of the $P_{x} G_{y} E^{z}$ composite. The regression analysis model for the flexural strength means and the flexural SN ratio is presented in Table 8 and Table 9 respectively. 
Table 8: Regression analysis model flexural strength mean

\begin{tabular}{ccccc}
\hline Predictor & Coef & SE Coef & T & P \\
\hline Constant & 432.589 & 276.289 & 1.56571 & 0.258 \\
PALF Content $(\%) ; \mathrm{x}$ & -32.643 & 21.226 & -1.53783 & 0.264 \\
Glass Fiber Content $(\%) ; \mathrm{y}$ & -1.599 & 10.370 & -0.15419 & 0.892 \\
Fiber Length (mm); z & -8.855 & 8.885 & -0.99653 & 0.424 \\
X*y & 0.836 & 0.700 & 1.19410 & 0.355 \\
X*z & 1.196 & 0.700 & 1.70820 & 0.230 \\
y*z & -0.635 & 0.700 & -0.90699 & 0.460 \\
\hline
\end{tabular}

$\mathrm{S}=18.9029 \quad \mathrm{R}-\mathrm{Sq}=77.57 \%$

The regression equation for the mean is given in equation (8)

$$
\text { Flexural Mean }=432.6-32.7 x-1.6 y-8.9 z+0.84 x^{*} y+1.2 x^{*} z-0.64 y^{*} z
$$

Table 8: Regression analysis model for flexural strength SN ratio

\begin{tabular}{ccccc}
\hline Predictor & Coef & SE Coef & T & P \\
\hline Constant & 65.5066 & 24.9746 & 2.62293 & 0.120 \\
PALF Content $(\%) ; \mathrm{x}$ & -2.5953 & 1.9187 & -1.35264 & 0.309 \\
Glass Fiber Content (\%); y & -0.0501 & 0.9374 & -0.05350 & 0.962 \\
Fiber Length (mm); z & -0.6649 & 0.8032 & -0.82786 & 0.495 \\
$\mathrm{X}^{* \mathrm{y}}$ & 0.0659 & 0.0633 & 1.04086 & 0.407 \\
$\mathrm{X}^{*} \mathrm{z}$ & 0.0956 & 0.0633 & 1.51008 & 0.270 \\
$\mathrm{y}^{*} \mathrm{z}$ & -0.0544 & 0.0633 & -0.85912 & 0.481 \\
\hline
\end{tabular}

$\mathrm{S}=1.70869 \quad \mathrm{R}-\mathrm{Sq}=71.04 \%$

The regression equation for $\mathrm{SN}$ ratio is given in equation (9)

Flexural SN Ratio $=65.5-2.6 x-0.0502 y-0.665 z+0.0659 x * y+0.0956 x * z-0.0544 y * z$

Mathematical models on the mean and $\mathrm{SN}$ ratio of the flexural strength of $\mathrm{P}_{\mathrm{x}} \mathrm{G}_{\mathrm{y}} \mathrm{E}^{\mathrm{z}}$ composite in regards to the factors considered for optimization are presented in Equations (8) and (9) respectively. The R-Sq of $77.57 \%$ for the means model and R-Sq of 71.04\% for the flexural SN ratio model indicates the suitability of the model to predict the flexural strength of the $\mathrm{P}_{\mathrm{x}} \mathrm{G}_{\mathrm{y}} \mathrm{E}^{z}$ composite with the conditions of the factors under study. This agreement of the predicted value with the actual experimental values of the means is shown in Figure 4. 


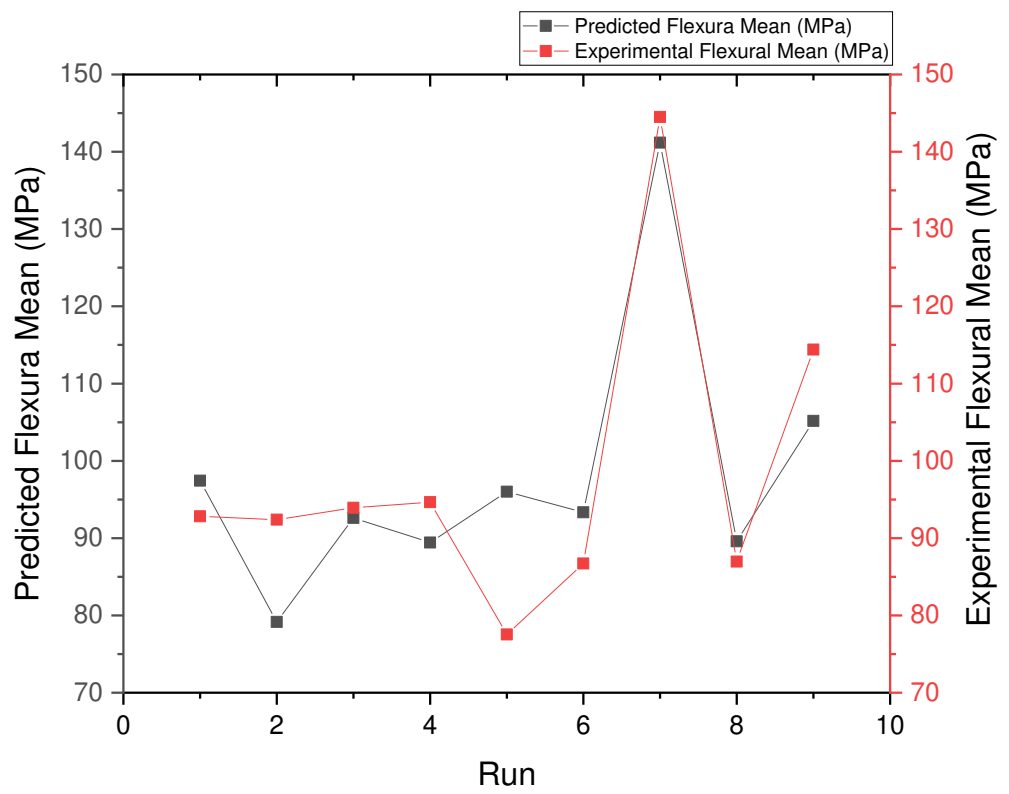

Figure 4: Modeled and experimental plot of flexural strength of $\mathrm{P}_{\mathrm{x}} \mathrm{G}_{\mathrm{y}} \mathrm{E}^{\mathrm{z}}$ hybrid composite

The result of the predicted flexural strength and the experimental values of the $\mathrm{P}_{20} \mathrm{G}_{20} \mathrm{E}^{25}$ hybrid composite which is at the optimal composition is compared in Table 9 where the error percentage is calculated from Equation 10.

The percentage error is calculated using Equation 8.

$$
\% \text { Error }=\frac{\text { Experimental value }- \text { Predictive Value }}{\text { Experimental Value }} \times 100
$$

Table 9: Confirmatory results comparison at the optimal level

\begin{tabular}{ccccc}
\hline & $\begin{array}{c}\text { Optimal Process } \\
\text { Parameter Settings }\end{array}$ & $\begin{array}{c}\text { Predictive Values } \\
\text { (MPa) }\end{array}$ & $\begin{array}{c}\text { Experimental } \\
\text { Values (MPa) }\end{array}$ & \% Error \\
\hline S/N ratio (dB) & x1y1z1 & 42.4755 & 43.1969 & 1.7 \\
$\begin{array}{c}\text { Flexural strength } \\
\text { (MPa) }\end{array}$ & x1y1z1 & 134.836 & 144.499 & 7.17 \\
\hline
\end{tabular}

\subsection{Conclusion}

In the optimization of the manufacturing parameters of a $P_{x} G_{y} E^{z}$ hybrid composite based on its flexural properties, experimental observations have verified that the flexural strength of the composite is best at a composition of PALF content volume at $20 \%$, glass fiber at $20 \%$ fiber content volume and fiber length at $25 \mathrm{~mm}$. Also, pineapple leaf fiber has the highest contribution to the flexural strength of the material. The regression equations developed predict to a good degree of reliability, the flexural strength of the $\mathrm{P}_{\mathrm{x}} \mathrm{G}_{\mathrm{y}} \mathrm{E}^{\mathrm{z}}$ composite at different combinations of its factors. 


\section{Declaration}

Funding: This research did not receive any funding

Conflicts of interest/Competing interests: On behalf of all authors, the corresponding author states that there is no conflict of interest.

Availability of data and material: Not applicable

Code availability: Not applicable

Ethics approval: Not applicable

Consent to participate: Not applicable

Consent for publication: Not applicable

\section{References}

Abdulqadir, H. R., Zeebaree, S. R., Shukur, H. M., Sadeeq, M. M., Salim, B. W., Salih, A. A., \& Kak, S. F. (2021). A study of moving from cloud computing to fog computing. Qubahan Academic Journal, 1(2), 60-70.

Ahmed Sabah, B. (2020). Sintering effect on the marginal fit and flexural strength of zirconia crowns.

Alhijazi, M., Safaei, B., Zeeshan, Q., Asmael, M., Eyvazian, A., \& Qin, Z. (2020). Recent developments in luffa natural fiber composites. Sustainability, 12(18), 7683.

Basavarajappa, S., Chandramohan, G. and Paulo, D.J. (2007) Application of Taguchi Techniques to Study Dry Sliding Wear Behaviour of Metal Matrix Composites. Materials and Design, 28, 1393-1398. http://dx.doi.org/10.1016/j.matdes.2006.01.006

Bratek-Skicki, A. (2021). Towards a new class of stimuli-responsive polymer-based materials-Recent advances and challenges. Applied Surface Science Advances, 4, 100068.

Estillore, J. V., Dungo, C. A., Guzman, K. N., Maniaul, J. M., \& Magdaluyo Jr, E. (2021). Optimal material selection study of prosthetic socket and pylon tube in transtibial prosthesis fabrication. Engineering Research Express, $3(2), 025030$.

Gangwar, S., Arya, P., \& Pathak, V. K. (2020). Optimal material selection for ship body based on fabricated zirconium dioxide/silicon carbide filled aluminium hybrid metal alloy composites using novel fuzzy based preference selection index. Silicon, 1-18.

Hardian, R., Liang, Z., Zhang, X., \& Szekely, G. (2020). Artificial intelligence: The silver bullet for sustainable materials development. Green Chemistry, 22(21), 7521-7528.

Hassan, T., Jamshaid, H., Mishra, R., Khan, M. Q., Petru, M., Novak, J., ... \& Hromasova, M. (2020). Acoustic, mechanical and thermal properties of green composites reinforced with natural fibers waste. Polymers, 12(3), 654.

Herrera-Franco, P., \& Valadez-Gonzalez, A. (2005). A study of the mechanical properties of short natural-fiber reinforced composites. Composites Part B: Engineering, 36(8), 597-608.

Jawahir, I. S., Schoop, J., Kaynak, Y., Balaji, A. K., Ghosh, R., \& Lu, T. (2020). Progress toward modeling and optimization of sustainable machining processes. Journal of Manufacturing Science and Engineering, 142(11), 110811. 
Jeyapragash, R., Srinivasan, V., Sathiyamurthy, S. (2020) Mechanical properties of natural fiber/particulate reinforced epoxy composites-A review of the literature. Mater. Today Proc. 22, 1223-1227.

Jiang, T., Duan, Q., Zhu, J., Liu, H., \& Yu, L. (2020). Starch-based biodegradable materials: Challenges and opportunities. Advanced Industrial and Engineering Polymer Research, 3(1), 8-18.

Kerni, L.; Singh, S.; Patnaik, A.; Kumar, N. (2020) A review on natural fiber reinforced composites. Mater. Today: Proc. 2020, 28, 1616-1621.

Lee C.H., Khalina A., Lee S.H., Padzil F.N.M., Ainun Z.M.A. (2020) Physical, Morphological, Structural, Thermal and Mechanical Properties of Pineapple Leaf Fibers. In: Jawaid M., Asim M., Tahir P., Nasir M. (eds) Pineapple Leaf Fibers. Green Energy and Technology. Springer, Singapore. https://doi.org/10.1007/978-98115-1416-6_6

Li, M., Pu, Y., Thomas, V. M., Yoo, C. G., Ozcan, S., Deng, Y., ... \& Ragauskas, A. J. (2020). Recent advancements of plant-based natural fiber-reinforced composites and their applications. Composites Part B: Engineering, 108254.

Madhu, P., Sanjay, M. R., Jawaid, M., Siengchin, S., Khan, A., \& Pruncu, C. I. (2020). A new study on effect of various chemical treatments on Agave Americana fiber for composite reinforcement: Physico-chemical, thermal, mechanical and morphological properties. Polymer Testing, 85, 106437.

Mekonnen, B. Y., \& Mamo, Y. J. (2020). Tensile and flexural analysis of a hybrid bamboo/jute fiber-reinforced composite with polyester matrix as a sustainable green material for wind turbine blades. International Journal of Engineering, 33(2), 314-319.

Mittal, M., \& Chaudhary, R. (2018). Development of Palf / Glass and Coir / Glass Fiber Reinforced Hybrid Epoxy Development of PALF / Glass and Coir / Glass Fiber Reinforced Hybrid Epoxy Composites. Journal of Materials Science and Surface Engineering, 6(5), 851-861. Https://Doi.Org/10.Jmsse/2348-8956/6-5.1

Mulenga, T. K., Ude, A. U., \& Vivekanandhan, C. (2021). Techniques for Modelling and Optimizing the Mechanical Properties of Natural Fiber Composites: A Review. Fibers, 9(1), 6.

Nagavally, R. R. (2016). Composite Materials - History, Types, Fabrication Techniques, Advantages, and Applications. International Journal of Advances in Science Engineering and Technology, 4(3), 87-92.

Nayak, S. Y., Satish, S. B., Sultan, M. T. H., Kini, C. R., Shenoy, K. R., Samant, R., ... \& Mustapha, F. (2020). Influence of fabric orientation and compression factor on the mechanical properties of 3D E-glass reinforced epoxy composites. Journal of Materials Research and Technology, 9(4), 8517-8527.

Nurazzi, N. M., Asyraf, M. R. M., Khalina, A., Abdullah, N., Aisyah, H. A., Rafiqah, S., ... \& Sapuan, S. M. (2021). A review on natural fiber reinforced polymer composite for bullet proof and ballistic applications. Polymers, 13(4), 646.

Okokpujie, I. P., Okonkwo, U. C., Bolu, C. A., Ohunakin, O. S., Agboola, M. G., \& Atayero, A. A. (2020). Implementation of multi-criteria decision method for selection of suitable material for development of horizontal wind turbine blade for sustainable energy generation. Heliyon, 6(1), e03142.

Omrani, E.; Menezes, P.L.; Rohatgi, P.K. (2016) State of the art on tribological behavior of polymer matrix composites reinforced with natural fibers in the green materials world. Eng. Sci. Technol. Int. J., 19, 717-736.

Ozkan, D., Gok, M. S., \& Karaoglanli, A. C. (2020). Carbon fiber reinforced polymer (CFRP) composite materials, their characteristic properties, industrial application areas and their machinability. In Engineering Design Applications III (pp. 235-253). Springer, Cham. 
Palani Kumar, K., Keshavan, D., Natarajan, E., Narayan, A., Ashok Kumar, K., Deepak, M., \& Freitas, L. I. (2021). Evaluation of mechanical properties of coconut flower cover fibre-reinforced polymer composites for industrial applications. Progress in Rubber, Plastics and Recycling Technology, 37(1), 3-18.

Pappu, A.; Thakur, V.K. (2017). Towards sustainable micro and nano composites from fly ash and natural fibers for multifunctional applications. Vacuum, 146, 375-385.

Parashar, S., \& Chawla, V. K. (2021). A systematic review on sustainable green fibre reinforced composite and their analytical models. Materials Today: Proceedings.

Parv, A. L., Deaky, B. A., \& Stasiak-Betlejewska, R. (2021). Sustainable manufacturing systems-a simulation model. In IOP Conference Series: Materials Science and Engineering (Vol. 1009, No. 1, p. 012045). IOP Publishing.

Paul, R., Ayers, G., Bergerson, J., Black, K., Brucker, T., Dawoud, C., ... \& Wood, D. (2021). NEW SUSTAINABLE SYSTEMS ENGINEERING PROGRAM PROPOSAL-MINDSET AND DEVELOPMENT. Proceedings of the Canadian Engineering Education Association (CEEA).

Periyasamy, A. P., \& Militky, J. (2020). Sustainability in Regenerated Textile Fibers. Sustainability in the Textile and Apparel Industries, 63.

Rajeshkumar, G., Hariharan, V., Indran, S., Sanjay, M. R., Siengchin, S., Maran, J. P., ... \& Karuppiah, P. (2021). Influence of sodium hydroxide $(\mathrm{NaOH})$ treatment on mechanical properties and morphological behaviour of Phoenix sp. fiber/epoxy composites. Journal of Polymers and the Environment, 29(3), 765-774.

Rajeshkumar, G., Ramakrishnan, S., Pugalenthi, T., \& Ravikumar, P. (2020). Performance of surface modified pineapple leaf fiber and its applications. In Pineapple leaf fibers (pp. 309-321). Springer, Singapore.

Rangappa, S. M., Siengchin, S., \& Dhakal, H. N. (2020). Green-composites: Ecofriendly and sustainability. Applied Science and Engineering Progress, 13(3), 183-184.

Reddy, P. V., Kumar, G. S., Krishnudu, D. M., \& Rao, H. R. (2020). Mechanical and wear performances of aluminiumbased metal matrix composites: a review. Journal of Bio-and Tribo-Corrosion, 6, 1-16.

Reis, R. H. M., Nunes, L. F., Oliveira, M. S., de Veiga Junior, V. F., Garcia Filho, F. D. C., Pinheiro, M. A., ... \& Monteiro, S. N. (2020). Guaruman fiber: Another possible reinforcement in composites. Journal of Materials Research and Technology, 9(1), 622-628.

Sanchez-Rexach, E., Johnston, T. G., Jehanno, C., Sardon, H., \& Nelson, A. (2020). Sustainable materials and chemical processes for additive manufacturing. Chemistry of Materials, 32(17), 7105-7119.

Sapuan, S. M. (2021). "Green" conceptual design toward design for environmental sustainability. In Design for Sustainability (pp. 3-23). Elsevier.

Shaharuzaman, M. A., Sapuan, S. M., \& Mansor, M. R. (2021). Sustainable materials selection: principles and applications. In Design for Sustainability (pp. 57-84). Elsevier.

Shalf, J. (2020). The future of computing beyond Moore's law. Philosophical Transactions of the Royal Society A, 378(2166), 20190061.

Taguchi, G. (1993) Taguchi on Robust Technology Development Methods. ASME Press, New York, 1-40. http://dx.doi.org/10.1115/1.800288.ch1

Taguchi, G. and Konishi, S. (1987) Taguchi Methods, Orthogonalarrays and Linear Graphs, Tools for Quality Engineering. American Supplier Institute, Dearborn, 35-38.

Tam, M. K., Meier, M. A., Zhang, L., Allen, D. T., Licence, P., \& Subramaniam, B. (2020). Expectations for Papers on Sustainable Materials in ACS Sustainable Chemistry \& Engineering. 
Tu, H., Zhu, M., Duan, B., \& Zhang, L. (2021). Recent progress in high-strength and robust regenerated cellulose materials. Advanced Materials, 33(28), 2000682.

Van Grootel, A., Chang, J., Wardle, B. L., \& Olivetti, E. (2020). Manufacturing variability drives significant environmental and economic impact: The case of carbon fiber reinforced polymer composites in the aerospace industry. Journal of Cleaner Production, 261, 121087.

Venkateshwaran, N.; Elayaperumal, A.; Sathiya, G.K. (2012) Prediction of tensile properties of hybrid-natural fiber composites. Compos. Part B Eng., 43, 793-796.

Vieira, P. S. C., de Souza, F. S., Cardoso, D. C. T., Vieira, J. D., \& de Andrade Silva, F. (2020). Influence of moderate/high temperatures on the residual flexural behavior of pultruded GFRP. Composites Part B: Engineering, 200, 108335.

Vijayakumar, S., Palanikumar, K. (2019) Mechanical Property Evaluation of Hybrid Reinforced Epoxy Composite. Mater. Today Proc., 16, 430-438.

Wang, C.; Zuo, Q.; Lin, T.; Anuar, N.I.S.; Salleh, K.M.; Gan, S.; Yousfani, S.H.S.; Zuo, H.; Zakaria, S. (2020) Predicting thermal conductivity and mechanical property of bamboo fibers/polypropylene nonwovens reinforced composites based on regression analysis. Int. Commun. Heat Mass Transf. 118, 104895.

Wang, K.F.; Wang, B.L. (2018) A mechanical degradation model for bidirectional natural fiber reinforced composites under hydrothermal ageing and applying in buckling and vibration analysis. Compos. Struct., 206, 594-600. 